\title{
Survey of big data management and analysis in anti-terrorist moral education
}

\author{
Lu Ling $^{1, a} \quad$ Xu Liang ${ }^{2, b}$ \\ ${ }^{1}$ Engineering of CAPF, Xi'an 710086, China; \\ ${ }^{2}$ Political College of PLA, Xi'an 710068, China. \\ asuoduoma19861216@sina.com, ${ }^{\mathrm{b}} 215548800 @ q q . c o m$
}

Keywords: analysis; big data; anti-terrorist; education.

\begin{abstract}
With the development of social and economy, many countries are faced up with threaten in terrorist. The big data is the inevitable trend of the future development of human society. Its emergence and rapid development are having and will have profound effects on all aspects of social life. In the aspect of anti-terrorist moral education, the era of big data will present the brand-new request and challenge. So we have lots of things to do to highlight the value of big data technologies in the field of anti-terrorist moral education.
\end{abstract}

\section{Introduction}

President Xi grasps the general trend of information society profoundly. He explicitly points out that we should not only adhere to the fundamental principle and system of anti-terrorist moral education work, but also actively promote the information, legalization standards of it. This important instruction points the right direction and provides basic rules for the work. In the world today, with the revolution in information technology changing with each passing day, the development and application of Internet, cloud computing and big data encouraged the integration between different disciplines to some extent and at the same time opened up new research methods and perspectives in innovative way.

\section{The characteristics of the big data}

The concept of big data was originally born in IT field, of which the subjective men, electronic equipment and other things in life have a strong relationship between each other from the aspect of ways of formation. They together produce rivers of data in Internet. Since this concept was put forward, big data has morphed from a mere name into a current modern research method which contains information gathering, analysis and mining. Just as Victor Mayer-Schonberger and Kenneth Cukier mentioned in the book The Age of Big Data, "Big data analytics is a technique that provides collection and systematic analysis for information dataflow which derived from human's actions in Internet. Through which we can make a scientific judgement on people's behavioral tendencies and lifestyle habits in a period of time and then provide accurate information for the organization to promote the decisions more scientific. Although the exploration of big data involves multiple dimensions, four are of the most significant, that is volume, variety, velocity and value.

\section{The challenges of big data in anti-terrorist moral education}

Marx said, "The people are the creators of history." In today's society, we can understand it as: people make history, while digit changes lives. In the age of big data, the new ideas and new trends which were triggered by the new media technology have caused a big impact on the original relatively stable value system of college students. This shock has brought unprecedented pressure and challenges to the anti-terrorist moral education in college and university, but also provides new carrier and opportunities for it. 


\section{Absorption and internalization}

There's a certain level of contradiction between the systematic with theory of the anti-terrorist moral education and the inconsistencies, intuitions exist in students' ways of thinking. The students under the age of big data background had been "no longer get information line by line, page by page, or in a linear way" ,but "linked to information in an intuitive and associative way." When we use this non-linear access to get the information, the contact of information will be loose, and initiate intuitive and imaginative thinking.

\section{Acceptance and Construction}

Those information sometimes differentiate and erode our traditional social belief systems, which makes teachers' authoritative knowledge were shaken gradually, the unified values being questioned and the orthodox value system being affected. Due to the flexibility, massive characteristic, openness, interactivity and virtual, big data reflects the characteristics about double-edged sword when it comes with the anti-terrorist moral work. These negative information make some college students lose themselves in big data and indulge their own behavior, reduce the sense of responsibility, as a result, their morality was weakened.

\section{Transformation and Innovation}

Due to the fact that there are many differences between the college students and the anti-terrorist moral educators when they meet the conditions like getting the data or searching for the information at the same time, the college students are always getting more comprehensive information, which contributes to a condition that the college student are more likely to choose the information they want in their own judgement, weakening the leading position of the anti-terrorist moral educators. What's more, because of the big data has the characteristics of fast, openness and pluralism, students can get the education of "getting out of the classroom". Those conditions turn the educators into the "dialoguers", who not only increases the difficulty of the education restriction, but also makes the students say good-bye to the long-term and imperceptible education, reducing the effectiveness of the anti-terrorist moral education.

\section{Strengthen the analysis about anti-terrorist moral education}

The big data has been highlighted its powerful social influence and scientific value. The Wall Street Journal even named the Big Data, the Intelligent Manufacturing and the Wireless Net Work as "three technological changes leading our future". In a nutshell, we anti-terrorist moral educators who are in face of those new challenges should take out our courage and wisdom, enhancing the consciousness of the data, focusing on data mining and data sharing. Only in this way can we win the future of the anti-terrorist moral education in the era of big data.

\section{Enhanced Data awareness}

The anti-terrorist moral educators of the colleges and universities should fully understand the concept of big data, learn and master its technical principles and applied skills, analyze the meeting point among the big data, the network of ideological, political education, and the anti-terrorist moral education of new media systematically. Educators should strive to get the dynamic and synchronization of the research status, problem analysis and the development of measures, explore how to make the big data play the transformative power in the anti-terrorist moral education. In practice, we have to pay attention to the way of using the multi-dimensional, real-time and comprehensive coverage of big data technology, develop the technology of information retrieval and screening crawling for college students, thus providing a strong technical support.

\section{Focus on data mining}

If we want to obtain more comprehensive information about the students' ideological dynamic, we need to establish a cross-border thinking consciousness, and discuss and analyze the obtained data from many aspects and levels with the help of sharing and convenience of the data and gathering different education body, departments and learning resources. Big data technology allows students to receive anti-terrorist moral education unconsciously, which reduces students' resentment to the education. Many college students who are in face of the conditions such as the failure in love or exam often express their thoughts on the WeChat, Micro-blog and forums to seek help. After 
data mining, data analysis and data calculation, we can find out the volatile object and give them a corresponding education or counseling.

\section{Enable data sharing}

The collection of students' data can not be only confined to internal university activity data, but also should be extended to all the social activities of college students, even the information before they entering the school. So I think it's important to build the mechanism about information exchanging and data sharing between institutions and institutions, institutions and families, institutions and societies. Research team of interdisciplinary-based research should be actively built, so that it can take full advantage of the various disciplines in the related topics, which effectively promotes the scientific development of anti-terrorist moral education.

\section{Summary}

In the age of big data, we need to deal with the relations between the management and analysis in anti-terrorist moral education. How to treat the data and how to make use of the data. We must keep pace with the era of Information Network and promote the anti-terrorist education work to be better with a big data-driven. It will give us a advice in order to cope the problem in anti-terrorist war.

\section{References}

[1] Holzle U. Brawny cores still beat wimpy cores, most of the time. IEEE Micro, 2010,30(4)

[2] Zheng L, Shen C, Tang L, et al. Using data techniques to address critical information exchange needs in disaster affected public-private networks. Proceedings of the $16^{\text {th }}$ ACM SIGKDD Conference Knowledge Discovery and Data Mining, Washington DC, USA, 2010:125-134

[3] Dong Y, Yin X S, Lian C, et al. Unleash the architecture power to accelerate big data processing. Journal of Computer Science and Technology, 2014 